\title{
CsSAD: a fatty acid desaturase gene involved in abiotic resistance in Camellia sinensis (L.)
}

\author{
Z.T. Ding ${ }^{1,2 *}$, J.Z. Shen ${ }^{1,2 *}$, L.L. Pan ${ }^{1,2}$, Y.U. Wang ${ }^{1,2}$, Y.S. Li ${ }^{3}$, Y. Wang ${ }^{4}$ and \\ H.W. Sun ${ }^{5}$ \\ ${ }^{1}$ Tea Research Institute, Qingdao Agricultural University, Qingdao, Shandong, \\ China \\ ${ }^{2}$ Qingdao Key Laboratory of Genetic Improvement and Breeding in Horticultural Plant, \\ Qingdao, Shandong, China \\ ${ }^{3}$ Fruit and Tea Technology Extension Station, Jinan, Shandong, China \\ ${ }^{4}$ Qingdao Fruit, Tea and Flower Workstation, Shandong, China \\ ${ }^{5}$ Taishan Academy of Forestry Science, Taian, Shandong, China \\ ${ }^{*}$ These authors contributed equally to this study. \\ Corresponding author: Y. Wang \\ E-mail: wangyutea@163.com
}

Genet. Mol. Res. 15 (1): gmr.15017512

Received August 25, 2015

Accepted November 4, 2015

Published March 4, 2016

DOI http://dx.doi.org/10.4238/gmr.15017512

ABSTRACT. Tea (Camellia sinensis L.) is a thermophilic evergreen woody plant that has poor cold tolerance. The $S A D$ gene plays a key role in regulating fatty acid synthesis and membrane lipid fluidity in response to temperature change. In this study, full-length $S A D$ cDNA was cloned from tea leaves using rapid amplification of CDNA ends and polymerase chain reaction (PCR)-based methods. Sequence analysis demonstrated that CsSAD had a high similarity to other corresponding cDNAs. At $25^{\circ} \mathrm{C}$, the CsSAD transcriptional level was highest in the leaf and lowest in the stem, but there was no obvious difference between the root and stem organs. CsSAD expression was investigated by reverse transcription-PCR, which showed that $\operatorname{CsSAD}$ was upregulated at $4^{\circ}$ and $-5^{\circ} \mathrm{C}$. At $25^{\circ} \mathrm{C}, \mathrm{CsSAD}$ 
was induced by polyethylene glycol, abscisic acid, and wounding, and a similar trend was observed at $4^{\circ} \mathrm{C}$, but the mean expression level at $4^{\circ} \mathrm{C}$ was lower than that at $25^{\circ} \mathrm{C}$. Under natural cold acclimation, the ' $\mathrm{CsCr05}$ variety's CSSAD expression level increased before decreasing. The CSSAD expression level in variety 'CsCr06' showed no obvious change at first, but rapidly increased to a maximum when the temperature was very low. Our study demonstrates that CsSAD is upregulated in response to different abiotic conditions, and that it is important to study the stress resistance of the tea plant, particularly in response to low temperature, drought, and wounding.

Key words: Camellia sinensis (L.); SAD; Abiotic stress; Gene expression; Polyethylene glycol; Abscisic acid

\section{INTRODUCTION}

Stearoyl-acyl carrier protein (ACP) desaturase (SAD, EC1.14.99.6) is a key enzyme in fatty acid synthesis. It is the main product of plant fatty acid synthesis, and the SAD-mediated catalysis of stearoyl-ACP to oleoyl-ACP is the starting point for the formation of unsaturated fatty acids (Byfield and Upchurch, 2007). Therefore, to a great degree, SAD determines the ratio of saturated to unsaturated fatty acids in higher plants, and this ratio is closely associated with many functions in plants (Somerville and Browse, 1996; Los and Murata, 1998), particularly in plants acclimated to low temperatures (Kodama et al., 1995; Lindqvist et al., 1996).

The $S A D$ gene was originally isolated and purified from Carthamus tinctorius and Persea americana, and the primary structure of $C$. tinctorius $S A D$ has been described (Thompson et al., 1991). The Fe-O-Fe cluster structure of Ricinus communis $S A D$ was detected using resonance Raman spectroscopy (Fox et al., 1994), and a crystal structure was revealed (Lindqvist et al., 1996). Although a fab2 mutant of Arabidopsis thaliana had an inactive $S A D$ and substantially increased stearic acid content, it still performed unsaturated fatty acid synthesis; the mutant exhibited a dwarf phenotype, which can tolerate high temperatures (Lightner et al., 1994). Therefore, SAD may play a key role in regulating fatty acid synthesis and membrane lipid fluidity in response to temperature change. SAD expression in Brassica napus cultivated at low temperature was upregulated, which resulted in elevated SAD protein levels (Tasseva et al., 2004). SAD overexpression in plants increases cold tolerance by increasing the desaturation of fatty acids, and membranes are less damaged (De Palma et al., 2008). The results of these studies indicate that it is possible to modify the composition of plant fatty acids by manipulating $S A D$.

$S A D$ cDNA has been extracted from a variety of plants, including Jatropha curcas (Tong et al., 2006), Helianthus annuus (Salas et al., 2008), Arabidopsis thaliana (Cao et al., 2010), Elaeis guineensis (Saed Taha et al., 2012), Chlorella zofingiensis (Liu et al., 2012), and rice (Shelley et al., 2013). Over $70 S A D$ sequences, or sequence fragments, are registered on GenBank, but $S A D$ from the tea plant, Camellia sinensis (L.) O. Kuntze, has not been characterized.

C. sinensis is thermophilic and has poor cold tolerance. The plant faces three main problems during the overwintering period: chilling or frost damage caused by chronic low temperatures, and snow or frost damage caused by heavy snowfall and glazed frost; water deficit caused by low rainfall and subnormal relative air humidity in winter; and cold or frost damage and wind damage caused by monsoons. The cell membrane is the most sensitive plant tissue to stress, particularly 
low temperature. Cell membrane damage caused by low temperature is the root cause of plant cold injury and death. Therefore, it is important to study the stress resistance of the tea plant, particularly in response to low temperature, drought, and wounding.

Several studies have been conducted in order to better understand the physiological characteristics and molecular regulation mechanisms of the tea plant (Zhang et al., 2010; Ma et al., 2012; Wang et al., 2012; Pan et al., 2013). In the present study, we cloned the CsSAD gene, analyzed its sequence characteristics, and studied its expression under low temperatures, abscisic acid (ABA) treatment, drought stress, and wounding at low temperature. We also analyzed CsSAD expression in different tissues, and examined the effects of CsSAD expression in two varieties that exhibited different resistance to low temperature. This is the first study that has characterized CSSAD, and its results increase our understanding of the mechanisms involved in abiotic stress.

\section{MATERIAL AND METHODS}

\section{Plant materials and treatments}

Healthy, uniform 1-year-old clonal tea (C. sinensis cv. Longjing43) seedlings were procured from the Chengyang Tea Research Station (36 $19^{\prime} \mathrm{N}, 120^{\circ} 23^{\prime} \mathrm{E}$ ), Qingdao Agricultural University, China, and grown in a growth chamber maintained at $25^{\circ} \pm 3^{\circ} \mathrm{C}$ for $16 \mathrm{~h}$ during the day and at $20^{\circ} \pm 3^{\circ} \mathrm{C}$ for $8 \mathrm{~h}$ at night with $75 \%$ relative humidity for 2 weeks. For the low-temperature stress treatment, the plants were subjected to either $4^{\circ}$ or $-5^{\circ} \mathrm{C}$. The plants that received the ABA treatment were sprayed with $0.1 \mathrm{mM} \mathrm{ABA}$. Polyethylene glycol (PEG) is often used to study drought resistance in plants (Song and Wang, 2002); therefore, for the drought treatment, the plants were sprayed with $20 \%$ PEG-6000. For the wounding treatment, plants were cut into approximately 5-15- $\mathrm{mm}$ long sections with a sterile razor blade. For the natural cooling process, two varieties (one with large leaves named 'CsCr05', the other with small leaves named 'CsCr06') were chosen. Leaf samples were harvested and photographs taken from October 17, 2013 until January 16, 2014. The third mature leaf from the top was harvested at different periods $(0,1,3,6,12$, and $24 \mathrm{~h})$ after treatment, immediately frozen in liquid nitrogen, and stored at $-70^{\circ} \mathrm{C}$ for analysis.

\section{Isolation of total RNA and preparation of CDNA}

Total RNA was isolated using an Easy-Spin ${ }^{\text {TM }}$ Rapid Plant Total RNA Extraction Kit (Yuanpinghao Biotechnology Co. Ltd., Beijing, China) following the manufacturer instructions. RNA was quantified by electrophoresis on a $1.2 \%(\mathrm{w} / \mathrm{v})$ agarose gel, which was visualized under ultraviolet light after staining with ethidium bromide. First-strand cDNA was obtained using a ReverTAid ${ }^{\text {Tm }}$ First-Strand cDNA Synthesis Kit (Thermo Scientific, USA) according to the manufacturer instructions. The RNA was stored at $-20^{\circ} \mathrm{C}$.

\section{CsSAD cloning}

Alignments of the cDNA sequences of Vernicia fordii (GenBank accession No. GU363502), Jatropha curcas (DQ084491), Vernicia montana (EU072353), Lotus corniculatus (DQ020280), and Glycine max (L34346) identified several conserved domains. The amino acid sequences were obtained from the National Center for Biotechnology Information (NCBI) GenBank database (http:// www.ncbi.nlm.nih.gov/). Two conserved regions were used to design sense and antisense degen- 
erate primers for $S A D$ amplification. The amplification of the middle fragment was performed using a pair of degenerated primers, S1 and S2. The 3'- and 5'-polymerase chain reaction (PCR) primers were designed based on the middle fragment sequences. A 3'-rapid amplification of cDNA ends (RACE)-PCR of SAD cDNA was initially conducted using the primer pair B26 and S5, and then by nested PCR using the primers B25 and S6. A 5'-RACE-PCR amplification was conducted by using the primers AAP and S3, followed by AUAP and S4. Based on the nucleotide sequences of the 5'- and 3'-RACE products, the primers S7 and S8 were used for the amplification of the complete coding sequence of CSSAD. The primers and their annealing temperatures are listed in Table 1.

PCRs were performed in a total reaction volume of $25 \mu \mathrm{L}$ that contained $2 \mu \mathrm{L}$ DNA tem-

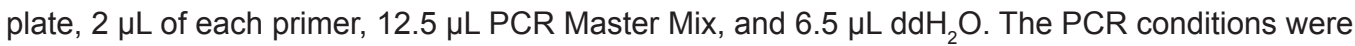
$94^{\circ} \mathrm{C}$ for $5 \mathrm{~min}, 94^{\circ} \mathrm{C}$ for $30 \mathrm{~s}, 57^{\circ} \mathrm{C}$ for $45 \mathrm{~s}, 72^{\circ} \mathrm{C}$ for $1 \mathrm{~min}$ for $35 \mathrm{cycles}$, and a final extension at $72^{\circ} \mathrm{C}$ for $10 \mathrm{~min}$. The PCR products were separated on $1.2 \%$ agarose gels and the targeted DNA fragments were recovered and cloned into a pTZ57R/T vector using a TA cloning ${ }^{\circledR}$ kit (Promega). The ligated products were transformed into Escherichia coli (DH5 $\alpha$ ) cells and sequenced by the Sangon Biotech Co., Shanghai, China.

\begin{tabular}{|c|c|c|c|}
\hline Primer & Sequence $\left(5^{\prime} \rightarrow 3^{\prime}\right)$ & Annealing temperature $\left({ }^{\circ} \mathrm{C}\right)$ & Usage \\
\hline $\begin{array}{l}\text { S1 } \\
\text { S2 }\end{array}$ & $\begin{array}{l}\text { AAGAAGCCWTTYAYKCCTCC } \\
\text { TACATSARGTGTGCHGGCAT }\end{array}$ & $\begin{array}{l}55.1 \\
54.3\end{array}$ & $\begin{array}{l}\text { for middle } \\
\text { fragments }\end{array}$ \\
\hline S3 & ATACATCATTCCAAGAGCGG & 57.6 & for 5' RACE \\
\hline S4 & CTTTGAGATTGACCCTGATG & 55.6 & for 3' RACE \\
\hline AAP & GGCCACGCGTCGACTAGTACGGGGGGGGGGGGGGGG & 81.4 & for full-length \\
\hline AUAP & GGCCACGCGTCGACTAGTAC & 63.9 & for RT-PCR \\
\hline S5 & ССTTTGСССТСТСССТTAGT & 59.7 & \\
\hline S6 & GTTGCCAACATTTCTCCACT & 57.6 & \\
\hline B25 & GACTCTAGACGACATCGA & 48.6 & \\
\hline B26 & GACTCTAGACGACATCGATTTTTTTTTTTTTTT & 66.1 & \\
\hline S7 & GCCTTTTAGCCCTCCTCATG & 61.1 & \\
\hline S8 & CTTCGCACAACAGTATTAAG & 51.3 & \\
\hline S9 & GCTAAGGACCACGCAGATAT & 56.9 & \\
\hline S10 & CTTTCCTCAAGCCGTCTAAT & 56.2 & \\
\hline GAPDH-F & TTGGCATCGTTGAGGGTCT & 61.6 & \\
\hline GAPDH-R & CAGTGGGAACACGGAAAGC & 61.7 & \\
\hline
\end{tabular}

RACE, rapid amplification of cDNA ends; RT-PCR, reverse transcription-polymerase chain reaction.

\section{Bioinformatic analysis}

The Primer Premier 5 software (http://www.Premierbiosoft.com) was used for all of the primer designs. Sequences of SAD proteins from a variety of plant species were obtained from the $\mathrm{NCBI}$ database for phylogenetic analysis. Multiple-sequence alignments and a phylogenetic tree were generated based on the neighbor-joining method in DNAMAN (Lynnon Biosoft). Subcellular localization was predicted using the PSORT tool (http://www.psort.org/), and EXPASY (http://www. expasy.cn/tools/) was used to predict the properties and structure of the protein (Gasteiger et al., 2005).

\section{Real-time quantitative reverse transcription (qRT)-PCR}

The primers S9 and S10 were synthesized based on a conserved region of the $S A D$ sequences obtained. The universal primers GAPDH-F and GAPDH-R were used as internal constitutively expressed controls (reference genes) for calculating the relative transcript abundance. 
All of the primers used for the qRT-PCR are listed in Table 1. The qRT-PCR was conducted using a Maxima ${ }^{\text {Tw }}$ SYBR ${ }^{\circledR}$ Green qPCR Master Mix (2X) Kit following the manufacturer protocol. A total of $2 \mu \mathrm{L} \mathrm{cDNA}$ was used as a template for the PCR. The PCR cycling conditions consisted of an initial polymerase activation step at $95^{\circ} \mathrm{C}$ for $10 \mathrm{~min}$, followed by 40 cycles at $95^{\circ} \mathrm{C}$ for $15 \mathrm{~s}$ and $57^{\circ} \mathrm{C}$ for $1 \mathrm{~min}$. The internal reference gene GADPH and target gene $S A D$ were analyzed on one plate, and the reactions were run in triplicate for each sample to ensure that the results were reproducible. An amplification curve was generated after analyzing the raw data and adjusting the cycle threshold $(\mathrm{Ct})$ value. The model $2^{-\Delta \Lambda \mathrm{Ct}}$ for comparing relative expression results under different treatments was used (Livak and Schmittgen, 2001). The number of targets, normalized to the reference control and relative to a calibrator, was given by $R=2^{-\Delta \Delta C t}$, where $2^{-\Delta \Delta C t}={ }^{\Delta C t}$ sample $-{ }^{\Delta C t}$ control. The final value obtained was a measure of the fold change in gene expression for the particular gene of interest between the treated samples and the untreated samples.

\section{RESULTS}

\section{Characterization of CsSAD}

The composite nucleotide sequence of the full-length $S A D$ cDNA was determined from cDNA clones by 3'- and 5'-RACE-PCR (Figure 1). The 1591-bp SAD cDNA contained a coding domain sequence of $1191 \mathrm{bp}$ and was flanked by 5'- and 3'-untranslated regions (UTRs) of 442 and 881 nucleotides, respectively. Its GenBank accession number is KC242133. The 999-bp coding domain sequence began with ATG at position 75 and ended with the termination codon TAA at position 1262. Based on the results of the multiple alignment of CsSAD with other SAD genes, the deduced amino acid sequence had two conserved domains: one belonged to the acyl-ACP desaturase family and the other to a ferritin-like family (Figure 2), which suggests that CsSAD belongs to both the acyl-ACP desaturase family and the ferritin-like family (Davydov et al., 2005; Tong et al., 2006). The phylogenetic analysis revealed that the CSSAD protein sequence had $80 \%$ identity with the $A$. thaliana SAD (AtSAD), 93\% identity with the Camellia oleifera SAD (CoSAD), and 86-90\% identity with other SAD genes (Figure 3). CSSAD had the greatest similarity to CoSAD, and a lower similarity to $A t S A D$ and the $B$. napus $S A D$.

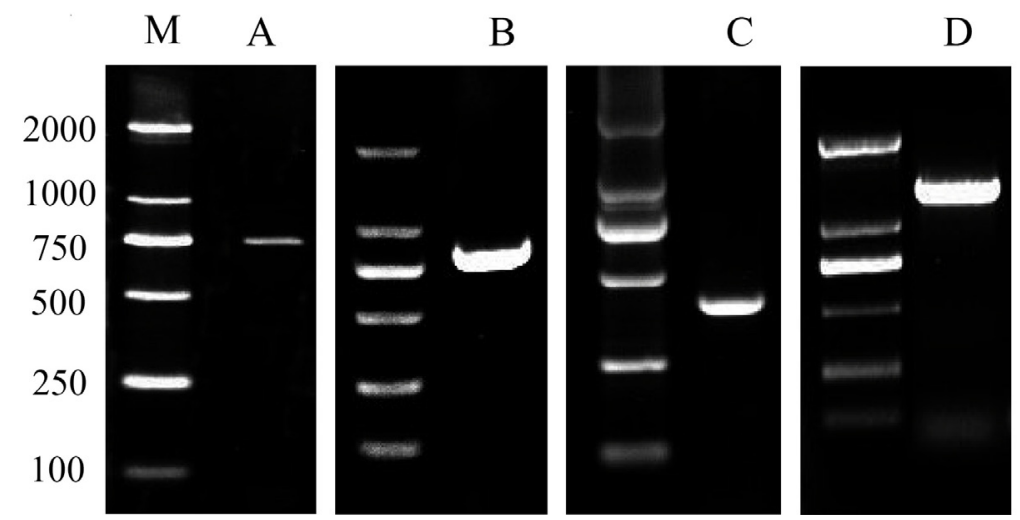

Figure 1. Isolation of $S A D$ from tea (Camellia sinensis). Lane $M$, marker; lanes $A-D$, middle fragment, 3'-fragment, 5 '-fragment, and full-length cDNA, respectively. 


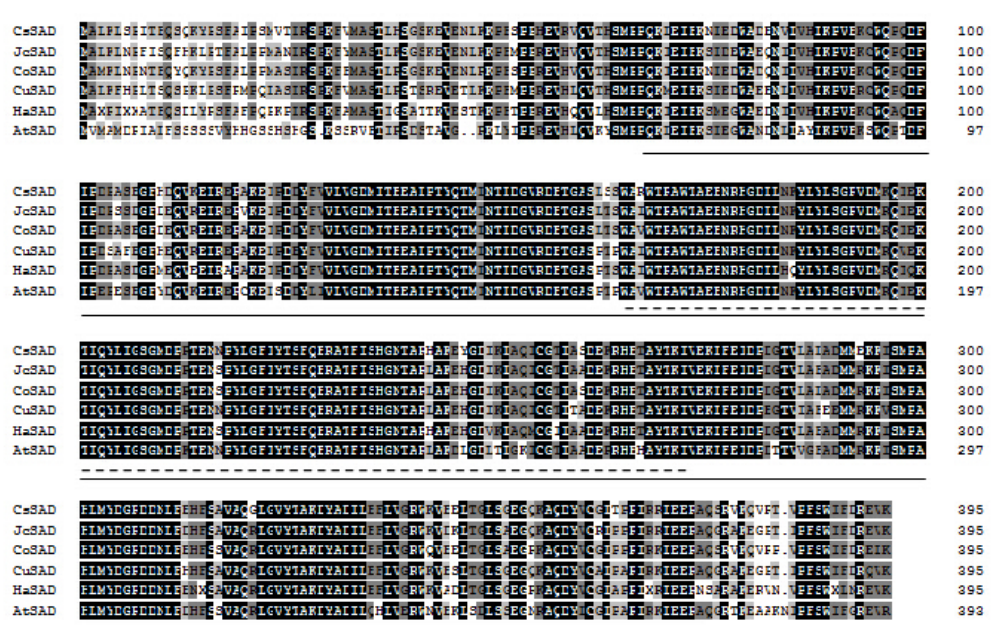

Figure 2. Alignments of predicted amino acid sequences of $S A D$ from different plant species. The acyl-ACP desaturase and ferritin-like family domains are underlined by solid and dashed lines, respectively. JCSAD, Jatropha curcas $S A D$; CoSAD, Camellia oleifera SAD; CuSAD, Cucumis sativus SAD; HaSAD, Helianthus annuus SAD; AtSAD, Arabidopsis thaliana $S A D$.

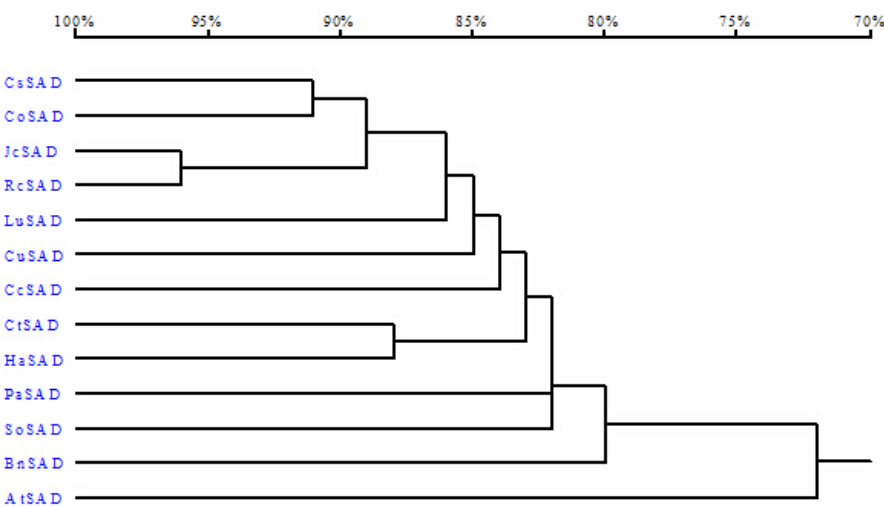

Figure 3. Phylogenetic tree of deduced SAD amino acid sequences in different plant species. The percentage values represent the putative protein sequence similarity between Camellia sinensis and other plants. CoSAD, Camellia oleifera SAD; JCSAD, Jatropha curcas SAD; RcSAD, Ricinus communis SAD; LuSAD, Linum usitatissimum SAD; CuSAD, Cucumis sativus SAD; CcSAD, Camellia chekiangoleosa SAD; CtSAD, Carthamus tinctorius SAD; HaSAD, Helianthus annuus SAD; PaSAD, Persea americana SAD; SoSAD, Spinacia oleracea SAD; BnSAD, Brassica napus $S A D ;$ AtSAD, Arabidopsis thaliana $S A D$.

\section{Sequence analysis of the CsSAD protein}

The deduced SAD protein was composed of 396 amino acids with a calculated molecular mass of $45.1 \mathrm{kDa}$, a theoretical isoelectric point of 6.42 , and an instability index of 30.98 . Based on the results of hydrophilic/hydrophobic analysis, we found that the hydrophilic part was higher than the hydrophobic part (Figure 4). Therefore, the CSSAD encoding product may be a hydrophilic protein. Subcellular localization of the deduced CSSAD amino acid sequence using the PSORT tool revealed that it was localized in the chloroplast. The secondary structure of the SAD protein 
was analyzed using SOPMA (Ullah et al., 2012), which revealed that it contained an alpha helix, an extended chain, a beta turn, and a random curl. These four structures accounted for 53.79, 8.33, 6.31 , and $31.57 \%$ of the total.

\section{CsSAD expression patterns in different organs}

We analyzed CSSAD expression patterns in different organs at different temperatures and periods (Figure $5 \mathrm{~A}-\mathrm{C}$ ). At $25^{\circ} \mathrm{C}$, the CsSAD transcriptional level was the highest in the leaf and lowest in the stem, and there was an obvious difference between them. Differences in CsSAD expression were found between three organs at $4^{\circ}$ and $-5^{\circ} \mathrm{C}$ (Figure $5 \mathrm{~B}$ and $\mathrm{C}$ ). At $4^{\circ} \mathrm{C}$, root $\mathrm{CsSAD}$ expression increased before decreasing within $3 \mathrm{~h}$, while it gradually increased in the leaf and stem. At $-5^{\circ} \mathrm{C}, \mathrm{CsSAD}$ expression increased before decreasing in each organ.

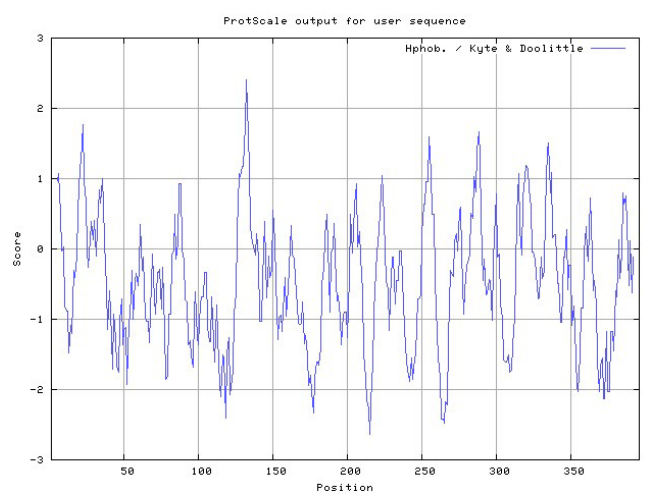

Figure 4. Hydrophilic analysis of the SAD cDNA encoding product from Camellia sinensis.
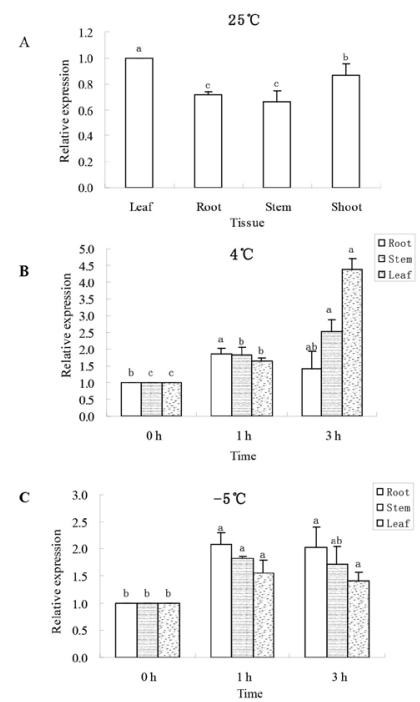

Figure 5. Relative CSSAD expression levels. A. CSSAD expression levels in different tissues at $25^{\circ} \mathrm{C}$. B. CsSAD expression levels in different tissues and at different time points at $4^{\circ} \mathrm{C}$. C. CsSAD expression levels in different tissues and at different time points at $-5^{\circ} \mathrm{C}$. 


\section{Leaf CsSAD expression in response to stress}

At $4^{\circ} \mathrm{C}, \mathrm{CsSAD}$ expression rapidly increased at $1 \mathrm{~h}$ after treatment, dramatically decreased at $3 \mathrm{~h}$, increased again at $6 \mathrm{~h}$, and then decreased to the previous level, with no significant change in the subsequent periods (Figure $6 \mathrm{~A}$ ). At $-5^{\circ} \mathrm{C}, \mathrm{CsSAD}$ expression increased at $1 \mathrm{~h}$, decreased slightly at $3 \mathrm{~h}$, remained at a stable level until $12 \mathrm{~h}$, before slightly increasing again at $24 \mathrm{~h}$. In general, the CsSAD expression level at $4^{\circ} \mathrm{C}$ was higher than that at $-5^{\circ} \mathrm{C}$, except at $24 \mathrm{~h}$, suggesting that the dark period between 16 and $24 \mathrm{~h}$ was involved in the upregulation of CsSAD.

At $25^{\circ}$ and $4^{\circ} \mathrm{C}$ after ABA treatment, CsSAD expression increased at first and then decreased, reaching its maximum at $6 \mathrm{~h}$ at $25^{\circ} \mathrm{C}$ and at $12 \mathrm{~h}$ at $4^{\circ} \mathrm{C}$, which suggests that low temperature could delay the response to ABA (Figure 6B).

After PEG treatment, CsSAD expression had increased after $1 \mathrm{~h}$ at $25^{\circ} \mathrm{C}$, decreased at 3 $\mathrm{h}$, and dramatically increased to a maximum at $12 \mathrm{~h}$ (Figure $6 \mathrm{C}$ ). At $4^{\circ} \mathrm{C}, \mathrm{CsSAD}$ expression dramatically increased after $1 \mathrm{~h}$, gradually decreased by $12 \mathrm{~h}$, and increased again at $24 \mathrm{~h}$. Therefore, tea plants take different times to respond to drought depending on the temperature, and a relatively low temperature could accelerate drought damage.

After wounding at $25^{\circ} \mathrm{C}$, CsSAD expression increased for $3 \mathrm{~h}$, decreased, then increased again at $24 \mathrm{~h}$ (Figure $6 \mathrm{D}$ ). At $4^{\circ} \mathrm{C}$, its expression increased for $6 \mathrm{~h}$, immediately decreased to its original level, and was barely discernable at $24 \mathrm{~h}$, suggesting that there was an interaction between wounding and low temperature.

A

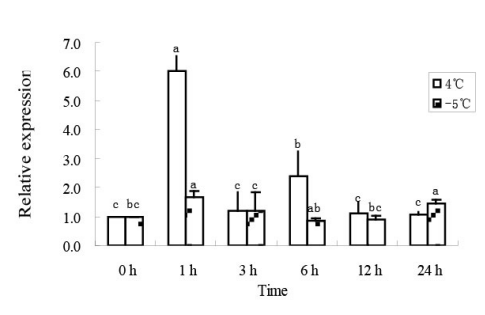

B 3.0
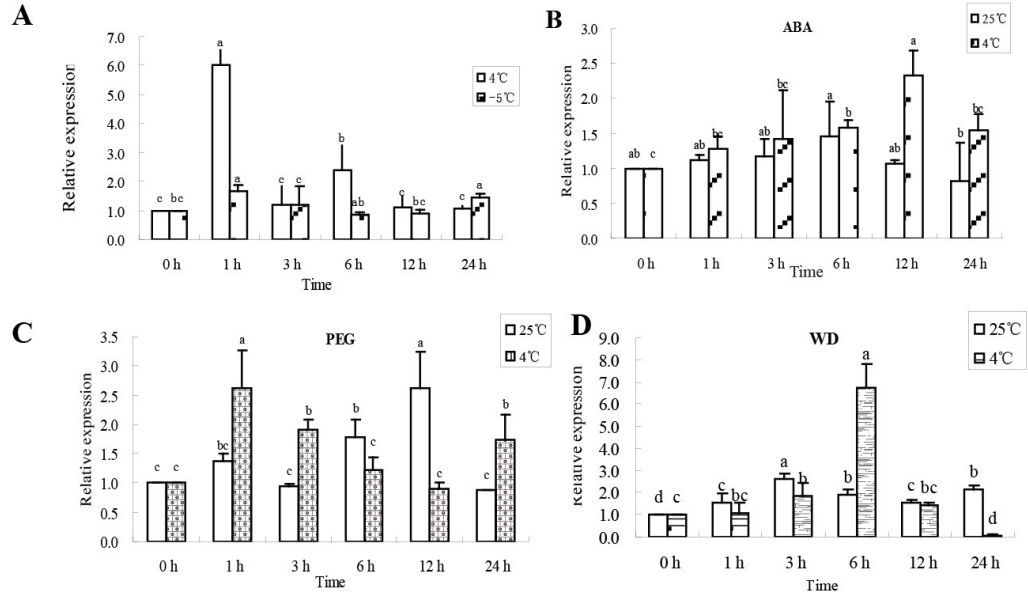

Figure 6. Relative CSSAD expression levels at different time points in response to different treatments. A. Low temperature. B. Abscisic acid (ABA). C. Polyethylene glycol (PEG). D. Wounding (WD).

\section{CsSAD expression during natural cold acclimation}

The temperature decreased from October 17, 2013 to January 16, 2014 (Figure 7A and $\mathrm{B})$, and CsSAD expression in 'CsCr05' increased at first before decreasing with the temperature; it reached its highest value on December 4. CsSAD expression in 'CsCr06' remained relatively stable, but dramatically increased to its maximum value on January 16 . These results suggest that CsSAD is upregulated in both 'CsCr05' and 'CsCr06' at low temperature, but they differ in their re- 
sponses over time, possibly because they have different sensitivities to low temperature. Changes in leaf color were similar in the two varieties (Figure $7 \mathrm{C}$ ). The leaves showed no visible signs of cold injury until November 13, when the leaves had lost their luster and had darkened. During the cold acclimation process, 'CsCr05' leaves became swollen and crinkled, before they turned red from the edge. Meanwhile, 'CsCr06' leaves turned yellow and brown, but cold damage occurred later than in 'CsCrO5'.

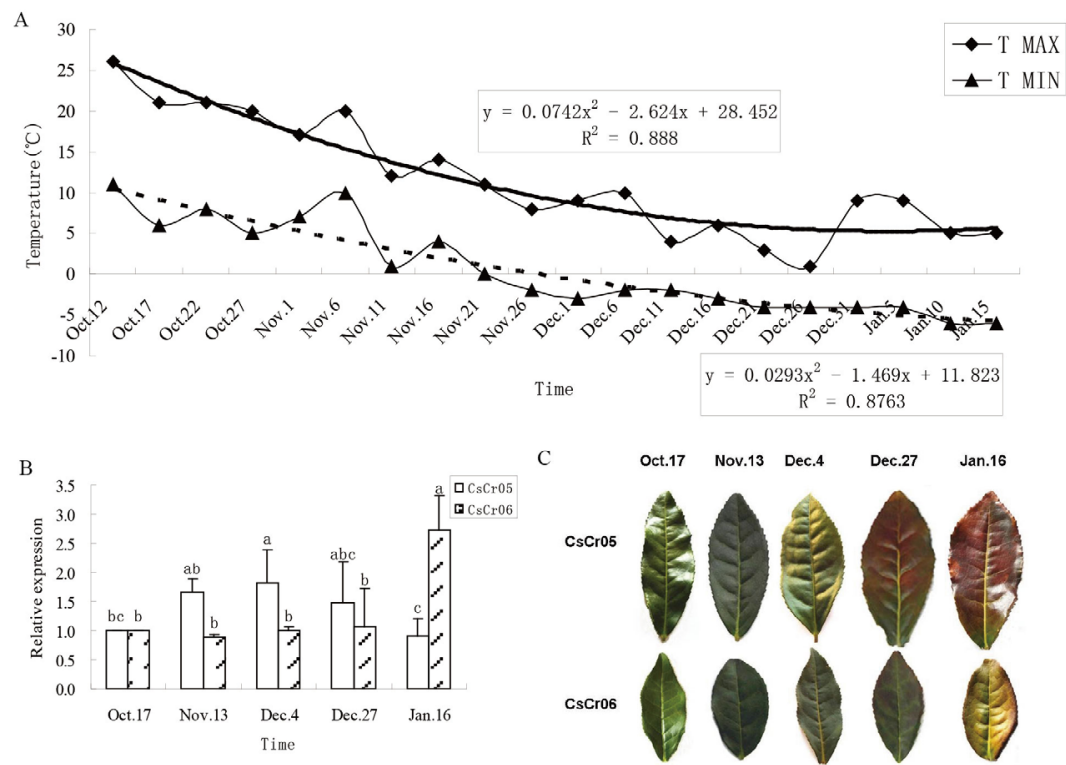

Figure 7. Transcription analysis of CSSAD during the natural cooling process. A. Changes in temperature and humidity during the natural cooling process. B. CSSAD transcription accumulation during the natural cooling process. C. Leafcolor changes in two varieties of Camellia sinensis during the natural cooling process.

\section{DISCUSSION}

SAD is involved in many plant processes that are based on catalyzing the desaturation of stearoyl-ACP, such as resistance to fungi and bacteria (Moche et al., 2003), maintenance of the crystalline liquid membrane (Los and Murata, 1998), regulation of growth, and the formation of storage oils (Zhang et al., 2008). In this study, a novel full-length $S A D$ gene was isolated from developing leaves of $C$. sinensis. The deduced CSSAD peptide sequence was highly homologous (79-93\% sequence identity) to other $S A D$ genes, which suggests that $S A D$ genes have been highly conserved during evolution.

We found that $\operatorname{CsSAD}$ expression is tissue-specific at the chilling temperature of $4^{\circ} \mathrm{C}$ and the freezing temperature of $-5^{\circ} \mathrm{C}$. At $25^{\circ} \mathrm{C}$, the $\mathrm{CsSAD}$ transcriptional level was highest in the leaf and lowest in the stem, and there were obvious differences between the organs, except between the stem and root. At $4^{\circ} \mathrm{C}$, different organs of the plants exhibited different responses at the same temperature. At $-5^{\circ} \mathrm{C}, \mathrm{CsSAD}$ expression in the roots was greater than that in the leaves, possibly because the quantity of synthesized unsaturated fatty acids in the roots was greater than in the leaves. This is consistent with the fact that the cold resistance of roots and stems is greater than that of leaves. Previous studies have also found that the expression of some SAD genes is tissue- 
specific. Zaborowska et al. (2002) found that SAD is moderately expressed in the leaves and stems of yellow lupine (Lupinus luteus). In lima bean (Phaseolus lunatus) plants, RT-PCR analysis revealed a high level of PISAD expression in the leaves, but few transcripts were found in the stems and roots (Zhang et al., 2011). In wild-type Arabidopsis plants, transcripts of most SAD genes have been reported in all of the tissues, and almost all $S A D$ genes (except for one) exhibit tissue specificity (Kachroo et al., 2006). They are expressed at different levels in the root, stem, and leaf tissues, suggesting tissue specificity expression abundance of the $S A D$ gene family. Other mechanisms, such as transcriptional and post-transcriptional regulation or substrate inhibition, might also be involved (Wang et al., 2013).

We found that CSSAD was upregulated by different degrees by ABA, drought, and wounding at low temperature and at $25^{\circ} \mathrm{C}$; however, at $4^{\circ} \mathrm{C}$, the maximum expression level occurred later than at $25^{\circ} \mathrm{C}$ after ABA treatment or wounding, whereas it occurred earlier after PEG treatment. This result indicates that low temperature may delay the response to ABA and wounding, but accelerates the response to drought stress. A large body of research suggests that temperature regulates fatty acid desaturase expression at both the transcriptional and post-transcriptional levels (Upchurch, 2008). Vega et al. (2004) reported an increase in SAD transcript levels in Solanum commersonii after cold acclimation, and suggested that this increase may be associated with an increase in freezing tolerance in the potato. $S A D$ transcript accumulation increased in the leaves of cold-acclimated S. commersonii leaves, but not in cultivated, non-acclimated varieties (Vega et al., 2004). The upregulation of CSSAD transcripts may be an important factor that contributes to the susceptibility to chilling that characterizes tea plants (Byfield and Upchurch, 2007). In this study, CSSAD expression patterns were investigated under stress conditions at low temperature, with ABA being the most important stressor. ABA is found extensively in plants (Lui and Li, 2001), plays a pivotal role in adaptive stress responses to environmental stimuli, and has been shown to induce the expression of a variety of genes (Liu et al., 2014). ABA increases in response to water deficit, and regulates root growth in order to maintain an adequate water supply during drought (Sharp et al., 2004). Several transgenic studies have improved drought tolerance by increasing ABA levels through the alteration of ABA biosynthetic and catabolic pathways (Sreenivasulu et al., 2012). It is not known which step in ABA biosynthesis is activated by mechanical damage. These findings indicate that in the plant kingdom, a variety of defense networks may function as a combination of different signals with a set of defense-related genes. Our results suggest that the ABA pathway does indeed play a significant role in the regulation of CSSAD expression.

Frost damage is caused by meteorological conditions such as low temperature, drought, and strong winds, which often occur together. Low temperature is the main reason for frost damage, while drought and wind often exacerbate the damage. Frost damage can also cause mechanical stress. We studied CsSAD expression levels in 'CsCr05' and 'CsCr06' during natural cold acclimation, and found that they increased and then decreased in 'CsCr05'. In 'CsCr06', they exhibited no obvious change at first, but increased to a maximum when the temperature was very low. Regarding the plants' leaves, frost damage started within the tip and edge of the uppermost leaves and then extended to the middle part of the blade, which turned yellow and brown. The mature leaves lost their luster and curled, before withering. Large-leaf varieties usually have thin leaves with a single layer of palisade tissue and thick, spongey tissue, and often suffer frost damage at $-5^{\circ} \mathrm{C}$, while medium- and small-leaf varieties can endure $-15^{\circ} \mathrm{C}$ for a short period; therefore, the cold and drought resistance of large-leaf varieties is poor. Because the leaves of small-leaf varieties contain multilayer palisade tissue, most of them have strong cold and drought resistance. This difference in cold resistance between different varieties is important when selecting cold-resistant germplasm resources. 
To the best of our knowledge, this is the first report on the cloning and expression of SAD in C. sinensis. Our data demonstrate that CsSAD participates in stress-response pathways induced by ABA, drought, wounding, and low temperature. Abiotic stress altered gene expression both positively and negatively, in a regulatory network with synergistic and antagonistic effects that has an important function in improving stress resistance in the tea plant. Future studies should investigate the mechanisms involved in this regulatory network, and how different regulating pathways interact.

\section{Conflicts of interest}

The authors declare no conflict of interest.

\section{ACKNOWLEDGMENTS}

Research supported by the Livelihood Project of Qingdao City (\#13-1-3-85-nsh), the Breeding Project of Shandong Province (\#2012LZ12-03, \#2013LZ12-03, and \#2014LZ12-03), the National Natural Science Foundation of China (\#31470027), and the Technology System of Modern Agricultural Industry in Shandong Province (\#SDAIT-21).

\section{REFERENCES}

Byfield GE and Upchurch RG (2007). Effect of temperature on delta-9 stearoyl-ACP and microsomal omega-6 desaturase gene expression and fatty acid content in developing soybean seeds. Crop Sci. 47: 1698-1704. http://dx.doi.org/10.2135/ cropsci2006.04.0213

Cao Y, Xian M, Yang J, Xu X, et al. (2010). Heterologous expression of stearoyl-acyl carrier protein desaturase (S-ACP-DES) from Arabidopsis thaliana in Escherichia coli. Protein Expr. Purif. 69: 209-214. http://dx.doi.org/10.1016/j.pep.2009.08.011

Davydov R, Behrouzian B, Smoukov S, Stubbe J, et al. (2005). Effect of substrate on the diiron(III) site in stearoyl acyl carrier protein $\delta$ 9-desaturase as disclosed by cryoreduction electron paramagnetic resonance/electron nuclear double resonance spectroscopy. Biochemistry 44: 1309-1315. http://dx.doi.org/10.1021/bi048599t

De Palma M, Grillo S, Massarelli I, Costa A, et al. (2008). Regulation of desaturase gene expression, changes in membrane lipid composition and freezing tolerance in potato plants. Mol. Breed. 21: 15-26. http://dx.doi.org/10.1007/s11032-0079105-y

Fox BG, Shanklin J, Ai J, Loehr TM, et al. (1994). Resonance Raman evidence for an Fe-O-Fe center in stearoyl-ACP desaturase. Primary sequence identity with other diiron-oxo proteins. Biochemistry 33: 12776-12786. http://dx.doi. org/10.1021/bi00209a008

Gasteiger E, Hoogland C, Gattiker A, Wilkins MR, et al. (2005). Protein identification and analysis tools on the ExPASy server. In: The proteomics protocols handbook (Walker JM, eds.). Humana Press, Totowa, NJ, USA, 571-607.

Kachroo A, Shanklin J, Whittle E, Lapchyk L, et al. (2006). The Arabidopsis stearoyl-acyl carrier protein-desaturase family and the contribution of leaf isoforms to oleic acid synthesis. Plant Mol. Biol. 63: 257-271. http://dx.doi.org/10.1007/s11103006-9086-y

Kodama H, Horiguchi G, Nishiuchi T, Nishimura M, et al. (1995). Fatty acid desaturation during chilling acclimation is one of the factors involved in conferring low-temperature tolerance to young tobacco leaves. Plant Physiol. 107: 1177-1185.

Lightner J, Wu J and Browse J (1994). A mutant of Arabidopsis with increased levels of stearic acid. Plant Physiol. 106: 14431451.

Lindqvist Y, Huang W, Schneider G and Shanklin J (1996). Crystal structure of delta9 stearoyl-acyl carrier protein desaturase from castor seed and its relationship to other di-iron proteins. EMBO J. 15: 4081-4092.

Liu J, Sun Z, Zhong Y, Huang J, et al. (2012). Stearoyl-acyl carrier protein desaturase gene from the oleaginous microalga Chlorella zofingiensis: cloning, characterization and transcriptional analysis. Planta 236: 1665-1676. http://dx.doi. org/10.1007/s00425-012-1718-7

Liu W, Wang Y and Gao C (2014). The ethylene response factor (ERF) genes from Tamarix hispida respond to salt, drought and ABA treatment. Trees (Berl.) 28: 317-327. http://dx.doi.org/10.1007/s00468-013-0950-5

Livak KJ and Schmittgen TD (2001). Analysis of relative gene expression data using real-time quantitative PCR and the $2^{-\Delta \Delta C t}$ Method. Methods 25: 402-408. http://dx.doi.org/10.1006/meth.2001.1262 
Los DA and Murata N (1998). Structure and expression of fatty acid desaturases. Biochim. Biophys. Acta 1394: 3-15. http:// dx.doi.org/10.1016/S0005-2760(98)00091-5

Lui H and Li L (2001). Regulating elements of gene expression induced by abscisic acid. Chin. Bull. Bot. 18: 8.

Ma N, Wang Y, Zhou K, Fu C, et al. (2012). Determination of fatty acid component of tea leaves with the nature temperature decrease. J. Qingdao Agr. Univ. 2: 5.

Moche M, Shanklin J, Ghoshal A and Lindqvist Y (2003). Azide and acetate complexes plus two iron-depleted crystal structures of the di-iron enzyme $\delta 9$ stearoyl-acyl carrier protein desaturase. Implications for oxygen activation and catalytic intermediates. J. Biol. Chem. 278: 25072-25080. http://dx.doi.org/10.1074/jbc.M301662200

Pan L-L, Wang Y, Hu J-H, Ding Z-T, et al. (2013). Analysis of codon use features of stearoyl-acyl carrier protein desaturase gene in Camellia sinensis. J. Theor. Biol. 334: 80-86. http://dx.doi.org/10.1016/j.jtbi.2013.06.006

Saed Taha R, Ismail I, Zainal Z and Abdullah SNA (2012). The stearoyl-acyl-carrier-protein desaturase promoter (Des) from oil palm confers fruit-specific GUS expression in transgenic tomato. J. Plant Physiol. 169: 1290-1300. http://dx.doi. org/10.1016/j.jplph.2012.05.001

Salas JJ, Youssar L, Martínez-Force E and Garcés R (2008). The biochemical characterization of a high-stearic acid sunflower mutant reveals the coordinated regulation of stearoyl-acyl carrier protein desaturases. Plant Physiol. Biochem. 46: 109116. http://dx.doi.org/10.1016/j.plaphy.2007.10.007

Sharp RE, Poroyko V, Hejlek LG, Spollen WG, et al. (2004). Root growth maintenance during water deficits: physiology to functional genomics. J. Exp. Bot. 55: 2343-2351. http://dx.doi.org/10.1093/jxb/erh276

Shelley IJ, Nishiuchi S, Shibata K and Inukai Y (2013). SLL1, which encodes a member of the stearoyl-acyl carrier protein fatty acid desaturase family, is involved in cell elongation in lateral roots via regulation of fatty acid content in rice. Plant Sci. 207: 12-17. http://dx.doi.org/10.1016/j.plantsci.2013.01.003

Somerville C and Browse J (1996). Dissecting desaturation: plants prove advantageous. Trends Cell Biol. 6: 148-153. http:// dx.doi.org/10.1016/0962-8924(96)10002-7

Song S and Wang Y (2002). [Molecular response of plant to drought stress]. Ying Yong Sheng Tai Xue Bao 13: $1037-1044$.

Sreenivasulu N, Harshavardhan VT, Govind G, Seiler C, et al. (2012). Contrapuntal role of ABA: does it mediate stress tolerance or plant growth retardation under long-term drought stress? Gene 506: 265-273. http://dx.doi.org/10.1016/j. gene.2012.06.076

Tasseva G, de Virville JD, Cantrel C, Moreau F, et al. (2004). Changes in the endoplasmic reticulum lipid properties in response to low temperature in Brassica napus. Plant Physiol. Biochem. 42: 811-822. http://dx.doi.org/10.1016/j.plaphy.2004.10.001

Thompson GA, Scherer DE, Foxall-Van Aken S, Kenny JW, et al. (1991). Primary structures of the precursor and mature forms of stearoyl-acyl carrier protein desaturase from safflower embryos and requirement of ferredoxin for enzyme activity. Proc. Natl. Acad. Sci. USA 88: 2578-2582. http://dx.doi.org/10.1073/pnas.88.6.2578

Tong L, Shu-Ming P, Wu-Yuan D, Dan-Wei M, et al. (2006). Characterization of a new stearoyl-acyl carrier protein desaturase gene from Jatropha curcas. Biotechnol. Lett. 28: 657-662. http://dx.doi.org/10.1007/s10529-006-0034-3

Ullah M, Hira J, Ghosh T, Ishaque N, et al. (2012). A Bioinformatics Approach for Homology Modeling and Binding Site Identification of Triosephosphate Isomerase from Plasmodium falciparum 3D7. J. Young Pharm. 4: 261-266. http://dx.doi. org/10.4103/0975-1483.104370

Upchurch RG (2008). Fatty acid unsaturation, mobilization, and regulation in the response of plants to stress. Biotechnol. Lett. 30: 967-977. http://dx.doi.org/10.1007/s10529-008-9639-z

Vega SE, Del Rio AH, Bamberg JB and Palta JP (2004). Evidence for the up-regulation of stearoyl-ACP (A9) desaturase gene expression during cold acclimation. Am. J. Potato Res. 81: 125-135. http://dx.doi.org/10.1007/BF02853610

Wang H, Cao F, Zhang W, Wang G, et al. (2013). Cloning and expression of stearoyl-acp desaturase and two oleate desaturases genes from Ginkgo biloba L. Plant Mol. Biol. Rep. 31: 633-648. http://dx.doi.org/10.1007/s11105-012-0525-4

Wang Y, Wang H and Ding Z-T (2012). Research on cold resistance of natural hybrid progenies of Camellia sinensis cv. Huangshanzhong. Shandong Agr. Sci. 5: 9

Zaborowska Z, Starzycki M, Femiak I, Swiderski M, et al. (2002). Yellow lupine gene encoding stearoyl-ACP desaturase-organization, expression and potential application. Acta Biochim. Pol. 49: 29-42.

Zhang P, Burton JW, Upchurch RG, Whittle E, et al. (2008). Mutations in a $\Delta$-stearoyl-ACP-desaturase gene are associated with enhanced stearic acid levels in soybean seeds. Crop Sci. 48: 2305-2313. http://dx.doi.org/10.2135/cropsci2008.02.0084

Zhang N, Hong Y-C, Wang Y and Ding Z-T (2010). Effects of abscisic acid and salicylic acid on several physiological indexes related to cold resistance of tea leaf during wintering period. Northern Hort. 22: 7.

Zhang YM, Wang CC, Hu HH and Yang L (2011). Cloning and expression of three fatty acid desaturase genes from coldsensitive lima bean (Phaseolus lunatus L.). Biotechnol. Lett. 33: 395-401. http://dx.doi.org/10.1007/s10529-010-0432-4 